\title{
ANALISIS MATEMATIK TERHADAP AZIMAT NUMERIK
}

\author{
Rosy Aliviana dan Abdussakir \\ Jurusan Matematika UIN Maulana Malik Ibrahim Malang \\ e-mail: rosy_aliviana@yahoo.com
}

\begin{abstract}
ABSTRAK
Matematika merupakan ilmu pengetahuan dasar yang tidak terlepas dari alam dan agama. Masyarakat saat ini masih banyak yang percaya tentang benda-benda yang membawa pada kesyirikan. Seperti halnya mempercayai dan menggunakan jimat. Jimat atau azimat atau tamimah merupakan sebuah bahan yang terdiri dari tulisan yang ditulis pada kertas, kain, kayu dan lain sebagainya yang dianggap mempunyai kesaktian dan dapat mengobati segala macam penyakit. Permasalahan yang diangkat dalam penelitian ini adalah konsep matematika apakah yang direpresentasikan dalam azimat numerik yaitu bagaimana penjelasan mengenai azimat numerik berdasarkan klasifikasi pada persegi ajaib (magic square). Langkahlangkah dalam menganalisis azimat numerik yaitu mengumpulkan azimat yang berbentuk kotak, mengidentifikasi pola-pola perhitungan persegi ajaib (magic square), mengklasifikasikannya dan menarik kesimpulan. Berdasarkan hasil penelitian diperoleh azimat yang dikhususkan dalam bentuk tabel menggunakan konsep persegi ajaib (magic square) dan diperoleh lima klasifikasi jenis dari konsep persegi ajaib yang terdapat dalam azimat numerik yaitu persegi semi-ajaib (semimagic square), persegi ajaib sempurna (perfect magic square), persegi ajaib simetris (symmetric magic square), persegi ajaib kosentrik (bondered), persegi ajaib penjumlahan-perkalian (addition-multiplication magic square), dan variasi persegi ajaib. Berdasarkan hasil analisis tersebut, azimat numerik yang berbentuk tabel $\mathrm{n} x \mathrm{n}$ secara matematika tidak mempunyai kekuatan apa-apa dan merupakan susunan bilangan dari persegi ajaib (magic square).
\end{abstract}

Kata Kunci: Bilangan, Azimat, Persegi Ajaib (Magic Square)

\section{PENDAHULUAN}

Matematika merupakan ilmu pengetahuan dasar yang dibutuhkan semua manusia dalam kehidupan sehari-hari baik secara langsung maupun tidak langsung. Matematika sendiri banyak membantu dan mempermudah untuk menyelesaikan permasalahan dalam kajian ilmuilmu yang lainnya, seperti halnya pada ilmu kedokteran, ilmu hukum, ilmu perbintangan, ilmu agama dan masih banyak ilmu-ilmu yang lainnya, bahkan dalam sebuah buku karangan Hairur Rahman (2007) dituliskan bahwa matematika merupakan ilmu yang tidak terlepas dari alam dan agama yang kebenarannya dapat dilihat dalam al-Qur'an. Oleh karena itu, hubungan antara matematika dengan ilmu agama memang sangat erat, sama seperti hubungan matematika dengan ilmu-ilmu yang lain.

Suatu ilmu dapat berkembang karena berbaur dengan ilmu-ilmu yang lain. Kebanyakan masyarakat kurang mengetahui bahwa perkembangan ilmu yang semakin pesat ini, dapat merubah hal yang tidak mungkin untuk dijelaskan menjadi suatu hal yang dapat dijelaskan secara rinci.

Sebuah buku karangan Abil (1994) dituliskan bahwa menurut konteks agama Islam, azimat dalam bentuk tulisan atau sering juga disebut wifiq adalah tulisan yang menggunakan simbol-simbol dalam bahasa Arab, baik berupa huruf, angka, gambar, maupun kombinasi ketiganya dan diyakini oleh kalangan Islam tradisional mempunyai khasiat atau kekuatan tertentu. Azimat terdiri dari tiga macam yaitu azimat numerik, azimat alfabetik dan azimat pictorial. Azimat dengan tulisan berupa angkaangka arab disebut azimat numeric, sedangkan azimat dengan tulisan berupa huruf-huruf Arab atau huruf Hijaiyah disebut azimat alfabetik. Azimat dengan tulisan berupa gambar-gambar tertentu disebut azimat pictorial.

Azimat numerik dapat dianalisis secara matematika karena menggunakan angka-angka atau simbol bilangan. Pada Gambar 1.1 di bawah ini merupakan salah satu contoh azimat numerik yang diambil dari kitab Al-Aufaq karangan $\mathrm{Al}$ Gozali:

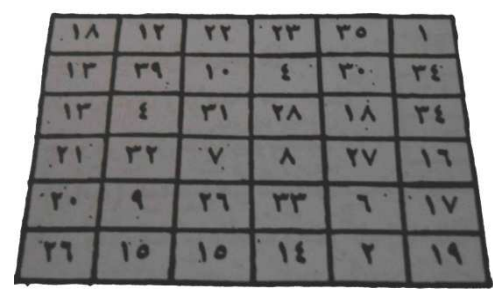

Gambar 1. Azimat Anak Cerdas

(Sumber: Al Gozali, halaman 15)

Azimat tersebut digunakan agar anak menjadi cerdas dan memperoleh ilmu yang tinggi. Dengan demikian, analisis matematika terhadap azimat numerik sangat mungkin untuk 
dilakukan agar dapat mengetahui rahasia-rahasia angka yang ada di dalam azimat tersebut.

Selama ini, masyarakat pengguna azimat tidak mengetahui secara rinci tentang azimat yang dipakai atau digunakannya. Mereka hanya meyakini bahwa azimat tersebut memang mempunyai kekuatan tanpa mengetahui apa sebenarnya yang tertulis dalam azimat tersebut.

Kalangan masyarakat muslim pedesaan pada umumnya dan sebagian masyarakat perkotaan, keberadaan azimat menjadi suatu yang sangat penting untuk membantu mengatasi berbagai permasalahan hidup, bahkan tidak sedikit orang yang sudah dianggap berpengetahuan luas dalam bidang agama juga memberikan azimat kepada masyarakat sebagai media untuk mengatasi masalah atau untuk kesaktian. Tidak jarang ada orang yang menjadikan azimat sebagai barang dagangan untuk diperjualbelikan. Keberadaan azimat ini oleh masyarakat diyakini tidak sekedar sebagai media, tetapi azimat itulah yang kemudian dianggap dapat membantu masyarakat dengan kekuatan yang dimilikinya.

Adapun batasan masalah pada penelitan ini adalah penulis hanya membatasi pada azimat numerik yang berbentuk tabel dengan konsep matematika yaitu persegi ajaib (magic square).

Tujuan dari penelitian ini adalah menjelaskan secara rinci mengenai azimat numerik berdasarkan klasifikasi matematikanya.

\section{KAJIAN TEORI}

\section{Numerik dan Sejarah bilangan}

Numerik dalam Kamus Besar Bahasa Indonesia memiliki arti yang berwujud nomor (angka); yang bersifat angka atau sistem angka. Sehingga dalam menyatakan bilangan, manusia menggunakan lambang atau simbol bilangan yang disebut angka (numeral).

Melihat perkembangan sejarahnya, simbol bilangan berbeda-beda berdasarkan kemajuan budaya suatu bangsa. Simbol bilangan suatu bangsa kadang merupakan hasil adopsi dan adaptasi dari simbol bilangan bangsa lainnya. Sejarah bilangan dimulai dari bangsa India pada abad ke-2 sebelum Masehi (SM) sampai abad ke6 M. Kemudian dikembangkan oleh bangsa Arab pada abad ke-7 sampai ke-9 M, bangsa Mesir Kuno, bangsa Sumeria, bangsa Babilonia dan kemudian bangsa Yunani. Sedangkan dalam matematika, untuk memudahkan uraian, penjelasan, atau keterangan, orang memerlukan seperangkat kesepakatan atau perjanjian tentang makna penggunakan lambang-lambang tertentu (Muhsetyo, 1997:5).

Metode paling awal yang digunakan oleh manusia merupakan sistem tallis dan sistem gambar. Sistem tallis mungkin merupakan metode yang paling awal digunakan manusia untuk melakukan pengecekan terhadap kuantitas-kuantitas tertentu. Dan pada sistem gambar, bilangan diwujudkan dengan pengulangan simbol-simbol yang mewakili objek tertentu.

Contoh dari sistem gambar adalah sebagai berikut:

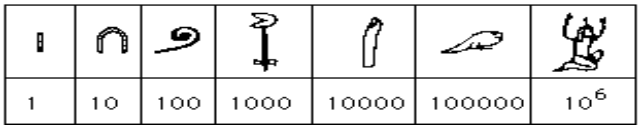

Gambar 2. Lambang Bilangan Mesir Kuno (Sumber: www-history.mcs.st-

andrew.ac.uk/HistTopics/Egyptian numerals.html)

Kemudian dikembangkan oleh bangsa Arab pada abad ke-7 sampai ke-9 M, bangsa Mesir Kuno, bangsa Sumeria, bangsa Babilonia dan kemudian bangsa Yunani.

Sebelum angka India masuk ke Arab sekitar abad ketujuh Masehi, bangsa Arab menggunakan huruf untuk melambangkan bilangan. Sistem ini dikenal dengan nama Huruf al-Jumal atau dikenal juga dengan nama Abjad, yang diambil dari empat huruf pertama. Berikut ini adalah tabel huruf al-Jumal bangsa Arab:

Tabel 1. Huruf al-Jumal

\begin{tabular}{|c|c|}
\hline Huruf & $\begin{array}{c}\text { Lambang } \\
\text { Desimal }\end{array}$ \\
\hline$I$ & 1 \\
\hline$ب$ & 2 \\
\hline$ج$ & 3 \\
\hline$د$ & 4 \\
\hline$\Delta$ & 5 \\
\hline$g$ & 6 \\
\hline$j$ & 7 \\
\hline$\tau$ & 8 \\
\hline$b$ & 9 \\
\hline 5 & 10 \\
\hline 5 & 20 \\
\hline$j$ & 30 \\
\hline$r$ & 40 \\
\hline$ن$ & 50 \\
\hline
\end{tabular}

\begin{tabular}{|c|c|}
\hline Huruf & $\begin{array}{c}\text { Lambang } \\
\text { Desimal }\end{array}$ \\
\hline س س & 60 \\
\hline$\varepsilon$ & 70 \\
\hline ف & 80 \\
\hline ص & 90 \\
\hline ق & 100 \\
\hline J & 200 \\
\hline ش & 300 \\
\hline$ت$ & 400 \\
\hline$\dot{H}$ & 500 \\
\hline$\dot{\tau}$ & 600 \\
\hline$j$ & 700 \\
\hline ض & 800 \\
\hline ظ & 900 \\
\hline$\dot{\varepsilon}$ & 1000 \\
\hline
\end{tabular}

Bangsa Mesir Kuno mempunyai tiga macam sistem numerasi, yaitu sistem hieroglyph hieratic dan demotic. Sistem hieroglyph merupakan sistem yang sangat kompleks untuk digunakan dalam kehidupan sehari-hari dan biasanya dituliskan pada batu. Sistem hieroglyph kemudian dikembangkan menjadi sistem yang lebih sederhana yang dikenal dengan sistem hieratic. Sistem hieratic digunakan oleh pendeta di kuil-kuil dan ditulis di daun papyrus sehingga dikenal pula dengan sistem kuil. Sistem demotic dikembangkan dari sistem hieratic dan menjadi sistem numerasi yang banyak digunakan dalam kehidupan sehari-hari. 
Berikut disajikan tabel perubahan secara bertahap angka Brahma menjadi angka desimal di Eropa (Abdussakir, 2009:54-57).

\begin{tabular}{|c|c|c|c|c|c|c|c|c|c|c|}
\hline Brahmi & & - & $=$ & $\equiv$ & + & $\mu$ & 6 & $?$ & $S$ & 7 \\
\hline Hindu & o & ? & 2 & ३ & $\gamma$ & $\varphi$ & $\xi$ & G & $c$ & $\xi$ \\
\hline Arabic & , & 1 & r & r & $\xi$ & 0 & 7 & V & $\Lambda$ & 9 \\
\hline Medieval & 0 & I & 2 & 3 & \& & c & 6 & 1 & 8 & 9 \\
\hline Modern & 0 & 1 & 2 & 3 & 4 & 5 & 6 & 7 & 8 & 9 \\
\hline
\end{tabular}

Gambar 3. Perubahan Angka India ke Angka Desimal (Sumber: http://www.archimedes-lab.org/numeral.html)

\section{Persegi Ajaib (Magic Square)}

\section{a. Sejarah Munculnya persegi ajaib}

Persegi ajaib ditemukan di Cina oleh raja Yu sekitar tahun $2200 \mathrm{sm}$. terdapat legenda bahwa dahulu kala terdapat bencana banjir di sekitar sungai kuning.

Saat raja Yu berusaha untuk menyalurkan air ke laut, terlihat kura-kura dengan pola titiktitik bulat bilangan yang diatur dalam suatu corak petak sembilan tiga aneh pada tempurung. Persegi ajaib yang ditemukan raja Yu tersebut disebut Lo Shu. Bilangan dalam Lo Shu ditunjukkan sebagai titik-titik atau noktah pada suatu tali. Lo Shu sebenarnya adalah persegi ajaib berukuran 3 x 3 (Alex. 2004:4).

\section{b. Pengertian Persegi Ajaib}

Sebuah buku karangan W. S Andrews (1960) dijelaskan bahwa persegi ajaib atau persegi magis (magic square) adalah susunan bilangan dalam kotak-kotak yang berbentuk persegi dengan sifat jumlah bilangan-bilangan menurut masing-masing baris, kolom, ataupun diagonalnya adalah sama. Persegi ajaib berukuran $n \times n$, sebanyak $n \times n$ bilangan disusun dalam kotak-kotak persegi dengan syarat tidak ada bilangan yang ditulis berulang dan jumlah bilangan-bilangan menurut masingmasing baris, kolom, ataupun diagonal adalah sama. Berikut ini adalah contoh persegi ajaib berukuran $3 \times 3,4 \times 4$ dan $5 \times 5$. Perhatikan bahwa jumlah bilangan pada masing-masing baris, kolom, dan diagonal adalah sama.

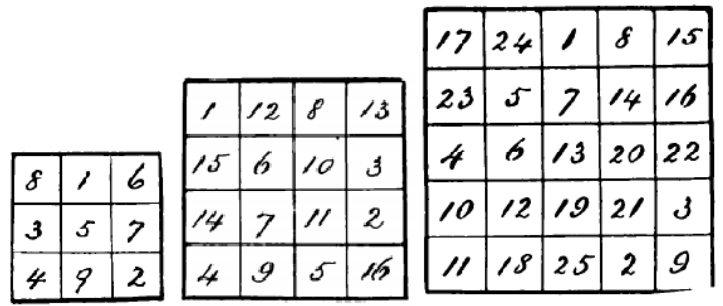

Gambar 4. Magic Square $3 \times 3,4 \times 4$ dan $5 \times 5$

\section{c. Klasifikasi Magic Square}

Terdapat tujuh klasifikasi dalam magic square yaitu sebagai berikut:
1. Persegi Semi-Ajaib (Semimagic Square) adalah sebuah matriks yang berukuran $n \times n$, jika dijumlahkan dari elemen setiap baris dan kolom adalah sama. Dengan mengabaikan jumlah kedua diagonal. Contoh persegi semi ajaib berukuran $5 \times 5$ adalah

$$
\left[\begin{array}{ccccc}
1 & 17 & 8 & 24 & 15 \\
7 & 23 & 14 & 5 & 16 \\
13 & 4 & 20 & 6 & 22 \\
19 & 10 & 21 & 12 & 3 \\
25 & 11 & 2 & 18 & 9
\end{array}\right]
$$

Jumlah bilangan pada baris dan kolom adalah sama, yaitu 65 .

2. Diabolik, Pandiagonal atau Persegi Ajaib Sempurna (Perfect Magic Square) adalah persegi ajaib jika ditambahkan maka jumlah dari setiap baris, kolom, diagonal utama dan diagonal kedua adalah sama atau konstan. Contoh jumlah pada persegi ajaib berukuran $3 \times 3$ yaitu 15 adalah

$$
\left[\begin{array}{lll}
4 & 9 & 2 \\
3 & 5 & 7 \\
8 & 1 & 6
\end{array}\right]
$$

3. Persegi Ajaib Simetris (Symmetric Magic Square) adalah persegi ajaib yang mempunyai jumlah dari dua sel dari setiap dua sel yang simetris dan dua sel ditengah maka jumlahnya sama. Persegi ajaib simetris juga disebut dengan associative magic square. Contoh persegi ajaib simetris ini adalah sebagai berikut:

Tabel 2. Persegi Ajaib 4 x 4

\begin{tabular}{|c|c|c|c|}
\hline 1 & 15 & 14 & 4 \\
\hline 12 & 6 & 7 & 9 \\
\hline 8 & 10 & 11 & 5 \\
\hline 13 & 3 & 2 & 16 \\
\hline
\end{tabular}

Jumlah setiap baris, kolom dan diagonalnya adalah 34, serta jumlah dari masing 2 sel pojok atas-bawah, kanan-kiri dan tengah adalah 34.

4. Persegi Ajaib Konsentrik atau Bordered adalah persegi ajaib yang menghilangkan bagian atas, bawah, kiri dan kanan kolom akan menghasilkan persegi ajaib lain. Contohnya adalah

$$
\left[\begin{array}{ccccccc}
4 & 5 & 6 & 43 & 39 & 38 & 40 \\
49 & 15 & 16 & 33 & 30 & 31 & 1 \\
48 & 37 & 22 & 27 & 26 & 13 & 2 \\
47 & 36 & 29 & 25 & 21 & 14 & 3 \\
8 & 18 & 24 & 23 & 28 & 32 & 42 \\
9 & 19 & 34 & 17 & 20 & 35 & 41 \\
10 & 45 & 44 & 7 & 11 & 12 & 42
\end{array}\right]
$$

Jumlah dari setiap kolom, baris dan kedua diagonal adalah 125 .

5. Sebuah Persegi Ajaib Nol atau (Zero Magic Square) adalah persegi ajaib yang jika dijumlahkan memiliki urutan baris, kolom, dan diaogonal adalah bilangan 0. Persegi ajaib normal ini mengandung bilangan negatif. 


$$
\left[\begin{array}{rrrrr}
4 & 11 & -12 & -5 & 2 \\
10 & -8 & -6 & 1 & 3 \\
-9 & -7 & 0 & 7 & 9 \\
-3 & -1 & 6 & 8 & -10 \\
-2 & 5 & 12 & -11 & -4
\end{array}\right]
$$

6. Persegi Ajaib Perkalian (Geometric) adalah Matriks persegi dari bilangan yang hasil setiap elemen baris, kolom, diagonal utama dan diagonal kedua adalah konstan. Contohnya adalah sebagai berikut:

$$
\left[\begin{array}{cccc}
432 & 6 & 18 & 16 \\
4 & 72 & 24 & 108 \\
8 & 36 & 12 & 216 \\
54 & 48 & 144 & 2
\end{array}\right]
$$

Jumlah setiap baris, kolom dan kedua diagonal adalah 746496.

7. Persegi Ajaib Penjumlahan-Perkalian (Addition-Multiplication Magic Square) adalah persegi ajaib dimana jika dijumlahkan dan dikalikan dalam setiap baris, kolom, dan kedua diagonal memiliki jumlah yang sama. Contohnya adalah

$\left[\begin{array}{cccccccc}162 & 207 & 51 & 26 & 133 & 120 & 116 & 25 \\ 105 & 152 & 100 & 29 & 138 & 243 & 39 & 34 \\ 92 & 27 & 91 & 136 & 45 & 38 & 150 & 261 \\ 57 & 30 & 174 & 225 & 108 & 23 & 119 & 104 \\ 58 & 75 & 171 & 90 & 17 & 52 & 216 & 161 \\ 13 & 68 & 184 & 189 & 50 & 87 & 135 & 114 \\ 200 & 203 & 15 & 76 & 117 & 102 & 46 & 81 \\ 153 & 78 & 54 & 69 & 232 & 175 & 19 & 60\end{array}\right]$

Jika setiap baris, kolom dan kedua diagonal dikalikan dan dijumlahkan hasilnya adalah 2,05 $\times 10^{15}$ (Stephens, 1993:5-7).

Pada perkembangan selanjutnya, terdapat berbagai variasi persegi ajaib yang muncul. Berikut ini juga merupakan persegi ajaib yang disebut IXOHOXI. Masing-masing baris, kolom, dan diagonal mempunyai jumlah 19998. Hal yang menarik dari persegi ajaib ini adalah jika dibalik (yang atas di bawah dan yang bawah di atas), tetap terbaca sebagai bujur sangkar ajaib.

Tabel 3. Persegi Ajaib IXOHOXI

\begin{tabular}{|l|l|l|l|}
\hline 1118 & 8181 & 1888 & 8811 \\
\hline 8888 & 1811 & 8118 & 1181 \\
\hline 8111 & 1188 & 8881 & 1818 \\
\hline 1881 & 8818 & 1111 & 8188 \\
\hline
\end{tabular}

\section{PEMBAHASAN}

\section{Klasifikasi Azimat Numerik Berdasarkan Konsep Persegi Ajaib (Magic Square)}

Azimat numerik merupakan azimat yang terdiri dari angka-angka atau simbol bilangan yang menggunakan bahasa Arab dan diyakini oleh kalangan Islam tradisional memiliki khasiat atau kekuatan tertentu. Analisis matematik tentang azimat numerik pada batasan masalah dikhususkan pada azimat berbentuk tabel yang memiliki konsep matematika yaitu persegi ajaib (magic square).
Berdasarkan jenis klasifikasi dari persegi ajaib (magic square), maka di bawah ini merupakan hasil analisis dari berbagai macam azimat numerik yang telah dikelompokkan.

\section{a. Persegi Semi-Ajaib (Semimagic Square)}

i. Azimat Hidup Sejahtera

Azimat ini digunakan agar hidup seseorang bisa sejahtera dan dilindungi dari murka Allah, serta diberikan panjang umur dan kekayaan yang melimpah. Azimat ini terbentuk dari Surat Al Ikhlas yang setiap huruf Al Jumal-nya dijumlahkan, yang terdiri dari:

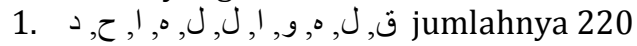

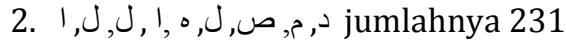

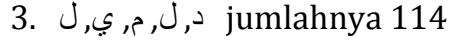

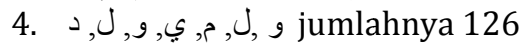

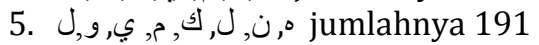

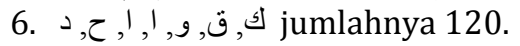

Bentuk azimatnya adalah sebagai berikut:

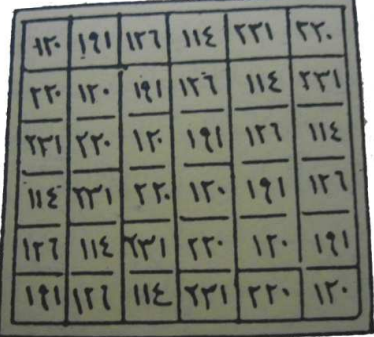

Gambar 5. Azimat Hidup Sejahtera

(Sumber: As Syadhli halaman 21)

Azimat di atas jika diterjemahkan ke dalam lambang desimal akan diperoleh hasil seperti tabel di bawah ini:

Tabel 4. Lambang desimal dari Azimat Hidup

\begin{tabular}{|l|l|l|l|l|l|}
\hline \multicolumn{7}{|c|}{ Sejahtera } \\
\hline 120 & 191 & 126 & 114 & 231 & 220 \\
\hline 220 & 120 & 191 & 126 & 114 & 231 \\
\hline 231 & 220 & 120 & 191 & 126 & 114 \\
\hline 114 & 231 & 220 & 120 & 191 & 126 \\
\hline 126 & 114 & 231 & 220 & 120 & 191 \\
\hline 191 & 126 & 114 & 231 & 220 & 120 \\
\hline
\end{tabular}

Berdasarkan hasil analisis numerik pada azimat diatas, jumlah setiap baris dan kolomnya adalah 1002, tetapi jumlah kedua diagonalnya berbeda yaitu 730 dan 1002. Maka azimat ini termasuk dalam persegi semi-ajaib (semimagic square) berukuran $6 \times 6$.

\section{b. Persegi Ajaib Sempurna (Perfect Magic Square)}

i. Azimat Penambah Barokah

Azimat ini digunakan apabila seseorang ingin menambah barokah dari Tuhan. Bentuk azimatnya dapat dilihat pada gambar 6 .

Azimat tersebut jika diterjemahkan ke dalam lambang desimal akan diperoleh hasil seperti tabel 5 . 


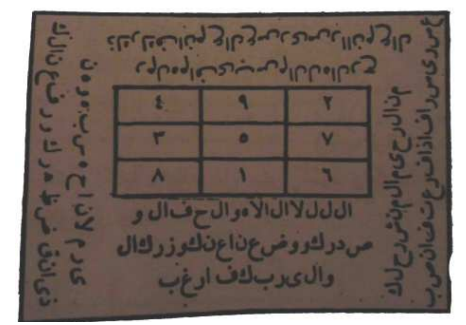

Gambar 6. Azimat Penambah Barokah (Sumber: Al Gozali halaman 5)

Tabel 5. Lambang Desimal dari Azimat Penambah

\begin{tabular}{|l|l|l|}
\multicolumn{3}{|c|}{ Barokah } \\
\hline 4 & 9 & 2 \\
\hline 3 & 5 & 7 \\
\hline 8 & 1 & 6 \\
\hline
\end{tabular}

Berdasarkan hasil analisis pada azimat di atas, jumlah dari setiap elemen pada masingmasing baris, kolom dan kedua diagonalnya adalah 15. Maka azimat tersebut termasuk dalam persegi ajaib sempurna atau perfect magic square berukuran $3 \times 3$.

ii. Azimat Mendapatkan Belas Kasih

Azimat ini digunakan agar mendapat belas kasih, pengayoman dari Tuhan dan diberi kecukupan dalam hidupnya. Azimat ini terbentuk dari:

1. ك, ا, ف, (Maha Mencukupi) jumlahnya 111

2. وو, ل, وي, في, (Maha Mengayomi) jumlahnya 56

3. و, د, و, و, د (Maha Belas Kasih) jumlahnya 10 (terdapat 2 huruf yang sama yaitu, dan $د$, maka dalam kitab dituliskan hanya dihitung 2 huruf saja).

Jumlah keseluruhannya 177. Bentuk azimatnya adalah sebagai berikut:

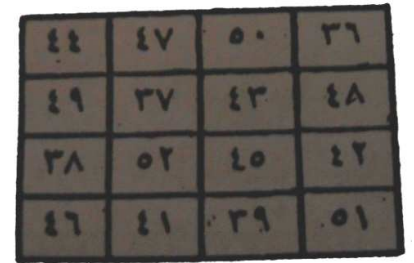

Gambar 7. Azimat Mendapatkan Belas Kasih (Sumber: Al Gozali Halaman 4)

Azimat di atas jika diterjemahkan ke dalam lambang desimal akan diperoleh hasil seperti tabel di bawah ini:

Tabel 6. Lambang Desimal dari Azimat Mendapatkan

\begin{tabular}{|l|l|l|l|}
\hline 44 & 47 & 50 & 36 \\
\hline 49 & 37 & 43 & 48 \\
\hline 38 & 52 & 45 & 42 \\
\hline 46 & 41 & 39 & 51 \\
\hline
\end{tabular}

Berdasarkan hasil analisis pada azimat di atas, jumlah dari setiap elemen pada masingmasing baris, kolom dan kedua diagonalnya adalah 177. Maka azimat tersebut termasuk dalam persegi ajaib sempurna atau perfect magic scuare berukuran $3 \times 3$.

\section{iii. Azimat Bermacam-macam Khasiat}

Azimat ini digunakan untuk melindungi diri, menjaga diri dari musuh, gangguan jin dan dari tipu daya manusia. Bentuk azimatnya adalah sebagai berikut:

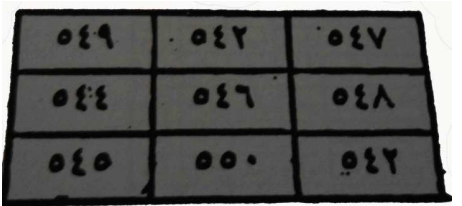

Gambar 8. Azimat Bermacam-macam Khasiat (Sumber: Kitab Al Gozali halaman 7)

Azimat di atas jika diterjemahkan kedalam lambang desimal akan diperoleh hasil seperti tabel di bawah ini:

Tabel 7. Lambang Desimal dari Azimat Bermacam-

macam Khasiat
\begin{tabular}{|l|l|l|}
\hline 549 & 542 & 547 \\
\hline 544 & 546 & 548 \\
\hline 545 & 550 & 543 \\
\hline
\end{tabular}

Berdasarkan hasil analisis pada azimat diatas, jumlah dari setiap elemen pada masingmasing baris, kolom dan kedua diagonalnya adalah 1638. Maka azimat tersebut termasuk dalam persegi ajaib sempurna atau perfect magic scuare berukuran $3 \times 3$.

iv. Azimat Mempercepat Jodoh

Azimat ini digunakan jika keluarga lakilaki atau perempuan uang belum bertemu dengan jodohnya walaupun sudah lanjut usia akan segera bertemu. Bentuk azimatnya adalah sebagai berikut:

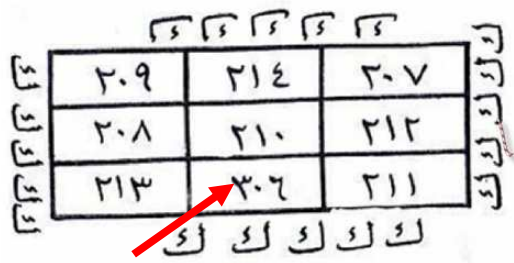

Gambar 9. Azimat Mempercepat Jodoh (Sumber: Halfeasy halaman 78-79)

Azimat di atas jika diterjemahkan ke dalam lambang desimal akan diperoleh hasil seperti tabel di bawah ini:

Tabel 8. Lambang Desimal dari Azimat Mempercepat

\begin{tabular}{|l|l|l|}
\multicolumn{3}{c}{ Jodoh } \\
\hline 209 & 214 & 207 \\
\hline 208 & 210 & 212 \\
\hline 213 & 306 & 211 \\
\hline
\end{tabular}

Berdasarkan hasil analisis pada azimat di atas, terdapat 1 kolom yang penulisannya kurang tepat. Jumlah dari elemen pada baris horisontal dan vertikal yang bersinggungan dengan kolom 
yang berwarna merah adalah 730. Sehingga, agar memenuhi syarat-syarat pada klasifikasi magic square angka 306 tersebut diganti dengan angka 206 seperti pada tabel di bawah ini:

Tabel 9. Lambang Desimal dari Azimat Mempercepat

\begin{tabular}{|l|l|l|}
\hline 209 & 214 & 207 \\
\hline 208 & 210 & 212 \\
\hline 213 & 206 & 211 \\
\hline
\end{tabular}

Berdasarkan hasil analisis pada azimat di atas, jumlah dari setiap elemen pada masingmasing baris, kolom dan kedua diagonalnya adalah 630. Maka azimat tersebut termasuk dalam persegi ajaib sempurna atau perfect magic scuare berukuran $3 \times 3$.

\section{c. Persegi Ajaib Kosentrik atau Bordered}

i. Azimat Memperlancar Berbicara

Azimat ini digunakan apabila seseorang ingin lancar saat berbicara atau setiap perkataan yang keluar dari isi hati. Bentuk azimatnya adalah sebagai berikut:

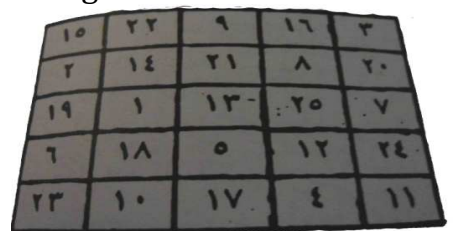

Gambar 10. Azimat Memperlancar Berbicara (Sumber: Al Gozali halaman 14)

Azimat di atas jika diterjemahkan ke dalam lambang desimal akan diperoleh hasil seperti tabel di bawah ini:

Tabel 10. Lambang Desimal dari Azimat

Memperlancar Berbicard
\begin{tabular}{|c|c|c|c|c|}
\hline 15 & 22 & 9 & 16 & 3 \\
\hline 2 & 14 & 21 & 8 & 20 \\
\hline 19 & 1 & 13 & 25 & 7 \\
\hline 6 & 18 & 5 & 12 & 24 \\
\hline 23 & 10 & 17 & 4 & 11 \\
\hline
\end{tabular}

Berdasarkan hasil analisis pada azimat di atas, jumlah dari setiap elemen pada masingmasing baris, kolom dan kedua diagonalnya adalah 39. Maka azimat tersebut termasuk dalam persegi ajaib kosentrik atau bordered yang mana jika bagian atas, bawah dan kiri, kanan kolom dihilangkan akan menghasilkan persegi ajaib (magic square) lain.

\section{d. Persegi Ajaib Simetris (Symmetric Magic Square)}

i. Azimat Menyiksa Musuh

Azimat ini digunakan jika seseorang ingin menyiksa musuhnya. Bentuk azimatnya adalah sebagai berikut:

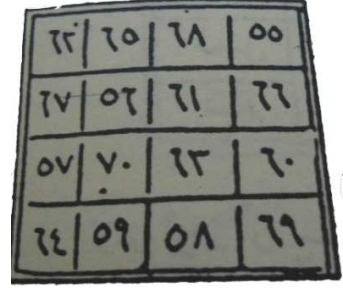

Gambar 11. Azimat Menyiksa Musuh

(Sumber: As-Syadli halaman 50)

Azimat di atas jika diterjemahkan ke dalam lambang desimal akan diperoleh hasil seperti tabel di bawah ini:

Tabel 11. Lambang Desimal dari Azimat Menyiksa

\begin{tabular}{|l|l|l|l|}
\multicolumn{4}{c}{ Musuh } \\
\hline 62 & 65 & 68 & 55 \\
\hline 67 & 56 & 61 & 66 \\
\hline 57 & 70 & 63 & 60 \\
\hline 64 & 59 & 58 & 69 \\
\hline
\end{tabular}

Berdasarkan hasil analisis pada azimat di atas, jumlah dari setiap elemen pada masingmasing baris, kolom dan kedua diagonalnya adalah 250. Maka azimat tersebut termasuk dalam persegi ajaib simetris atau symmetric magic square.

\section{ii. Azimat Pengobat Rasa Takut}

Azimat ini digunakan untuk menghilangkan rasa takut dihati dan memberi rasa aman dan keselamatan pada diri. Bentuk azimatnya adalah sebagai berikut:

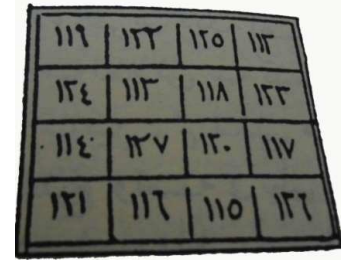

Gambar 12. Azimat Pengobat Rasa Takut (Sumber: As-Syadhli halaman 50)

Azimat di atas jika diterjemahkan ke dalam lambang desimal akan diperoleh hasil seperti tabel di bawah ini:

Tabel 12. Lambang Desimal dari Azimat Pengobat

\begin{tabular}{|l|l|l|l|}
\multicolumn{5}{c}{ Rasa Takut } \\
\hline 119 & 122 & 125 & 112 \\
\hline 124 & 113 & 118 & 123 \\
\hline 114 & 127 & 120 & 117 \\
\hline 121 & 116 & 115 & 126 \\
\hline
\end{tabular}

Berdasarkan hasil analisis pada azimat di atas, jumlah dari setiap elemen pada masingmasing baris, kolom dan kedua diagonalnya adalah 478. Maka azimat tersebut termasuk dalam persegi ajaib simetris atau symmetric magic square.

iii. Azimat Bermacam-macam Manfaat

Azimat ini digunakan untuk melindungi diri dari gangguan orang jahat selama perjalanan, 
keluar rumah, dan dimudahkan rizkinya. Bentuk azimatnya adalah sebagai berikut:

\begin{tabular}{|c|c|c|c|}
\hline TV & $r$ & $r$ & 5. \\
\hline rr & $\mathrm{TI}$ & $\Gamma T$ & $\Gamma$ \\
\hline$T T$ & ro & $T \Lambda$ & 10 \\
\hline Tq & $T_{\varepsilon}$ & Tr & $r \varepsilon$ \\
\hline
\end{tabular}

Gambar 13. Azimat Bermacam-macam Manfaat (Sumber: As-Syadhli halaman 53)

Azimat di atas jika diterjemahkan ke dalam lambang desimal akan diperoleh hasil seperti tabel di bawah ini:

Tabel 13. Lambang Desimal dari Azimat Bermacammacam Manfaat

\begin{tabular}{|l|l|l|l|}
\hline 27 & 30 & 33 & 20 \\
\hline 32 & 21 & 26 & 31 \\
\hline 22 & 35 & 28 & 25 \\
\hline 29 & 24 & 23 & 34 \\
\hline
\end{tabular}

Berdasarkan hasil analisis pada azimat diatas, jumlah dari setiap elemen pada masingmasing baris, kolom dan kedua diagonalnya adalah 110. Maka azimat tersebut termasuk dalam persegi ajaib simetris atau symmetric magic square.

\section{iv. Azimat Memikat Orang}

Azimat ini digunakan apabila seseorang ingin siapa saja yang memandangnya akan hanyut atau terpikat. Bentuk azimatnya adalah sebagai berikut:

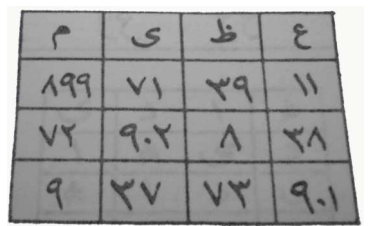

Gambar 14. Azimat Memikat Orang

(Sumber: Abbas halaman 79)

Azimat di atas jika diterjemahkan ke dalam lambang desimal akan diperoleh hasil seperti tabel di bawah ini:

Tabel 14. Lambang Desimal dari Azimat Memikat

\begin{tabular}{|c|c|c|c|}
\hline 40 & 10 & 900 & 70 \\
\hline 899 & 71 & 39 & 11 \\
\hline 72 & 902 & 8 & 38 \\
\hline 9 & 37 & 73 & 901 \\
\hline
\end{tabular}

Berdasarkan hasil analisis pada azimat di atas, jumlah dari setiap elemen pada masingmasing baris, kolom dan kedua diagonalnya adalah 1020. Maka azimat tersebut termasuk dalam persegi ajaib simetris atau symmetric magic square.

\section{e. Persegi Ajaib Penjumlahan-Perkalian (Addition-Multiplication Magic Square)}

i. Azimat Kekuatan

Azimat ini digunakan agar semua orang tunduk kepadanya dan apapun yang diinginkan akan tercapai. Bentuk azimatnya adalah sebagai berikut:

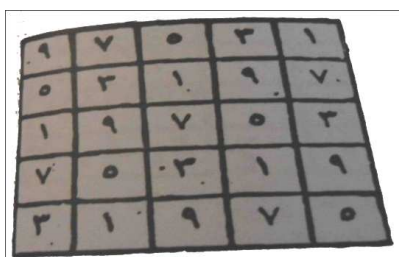

Gambar 15. Azimat Kekuatan

(Sumber: Al Gozali halaman 12)

Azimat di atas jika diterjemahkan ke dalam lambang desimal akan diperoleh hasil seperti tabel di bawah ini:

Tabel 15. Lambang Desimal dari Azimat Kekuatan

\begin{tabular}{|l|l|l|l|l|}
\hline 9 & 7 & 5 & 3 & 1 \\
\hline 5 & 3 & 1 & 9 & 7 \\
\hline 1 & 9 & 7 & 5 & 3 \\
\hline 7 & 5 & 3 & 1 & 9 \\
\hline 3 & 1 & 9 & 7 & 5 \\
\hline
\end{tabular}

Berdasarkan hasil analisis pada azimat di atas, jumlah dari setiap elemen pada masingmasing baris, kolom dan kedua diagonalnya adalah 25. Maka azimat tersebut termasuk dalam persegi ajaib penjumlahan-perkalian (additionmultiplication magic square).

\section{ii. Azimat Keselamatan}

Azimat ini digunakan agar tidak terjerumus ketempat yang nista dan apabila dibenci orang, maka orang tersebut tidak akan membenci lagi, diibaratkan besi yang leleh dengan bara api. Bentuk azimatnya adalah sebagai berikut:

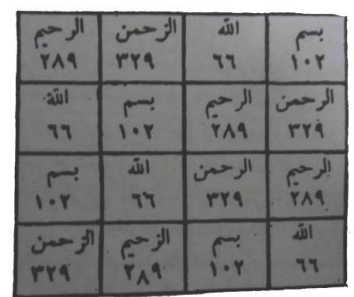

Gambar 16. Azimat Keselamatan

(Sumber: Al Gozali halaman 37)

Azimat di atas jika diterjemahkan ke dalam lambang desimal akan diperoleh hasil seperti tabel di bawah ini:

Tabel 16. Lambang Desimal dari Azimat Keselamatan

\begin{tabular}{|c|c|c|c|}
\hline 289 & 329 & 66 & 102 \\
\hline 66 & 102 & 289 & 329 \\
\hline 102 & 66 & 329 & 289 \\
\hline 329 & 289 & 102 & 66 \\
\hline
\end{tabular}

Berdasarkan hasil analisis pada azimat di atas, jumlah dari setiap elemen pada masingmasing baris, kolom dan kedua diagonalnya adalah 786 .

Maka azimat tersebut termasuk dalam persegi ajaib penjumlahan-perkalian (additionmultiplication magic square). 


\section{f. Variasi Persegi Ajaib}

i. Azimat Memerangi Hawa Nafsu

Azimat ini digunakan untuk memerangi hawa nafsu yang dimiliki manusia. Bentuk azimatnya adalah sebagai berikut:

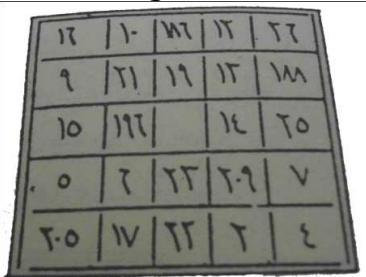

Gambar 17. Azimat Memerangi Hawa Nafsu (Sumber: As Syadhli halaman 43)

Azimat di atas jika diterjemahkan ke dalam lambang desimal akan diperoleh hasil seperti tabel di bawah ini:

Tabel 17. Lambang Desimal dari Azimat Memerangi Hawa Nafsu

\begin{tabular}{|c|c|c|c|c|}
\hline 16 & 10 & 186 & 12 & 26 \\
\hline 9 & 21 & 19 & 13 & 188 \\
\hline 15 & 196 & & 14 & 25 \\
\hline 5 & 6 & 23 & 209 & 7 \\
\hline 205 & 17 & 22 & 2 & 4 \\
\hline
\end{tabular}

Berdasarkan hasil analisis pada azimat di atas, jumlah dari setiap elemen pada masingmasing baris, kolom dan kedua diagonalnya adalah 250. Maka azimat tersebut termasuk dalam variasi dari persegi ajaib (magic square).

\section{ii. Azimat Memperbanyak Rizki}

Azimat ini digunakan untuk memperbanyak rizki dan mendapatkan barokah dari Allah. Bentuk azimatnya adalah sebagai berikut:

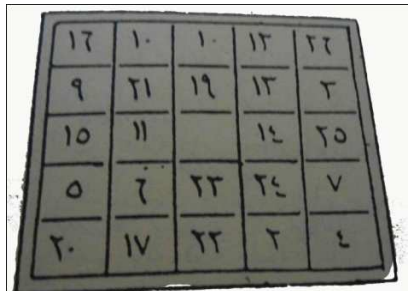

Gambar 18. Azimat Memperbanyak Rizki

(Sumber: As Syadhli Jalil halaman 44)

Azimat di atas jika diterjemahkan ke dalam lambang desimal akan diperoleh hasil seperti tabel di bawah ini:

Tabel 18. Lambang Desimal dari Azimat

\begin{tabular}{|c|c|c|c|c|}
\multicolumn{6}{|c|}{ Memperbanyak Rizki } \\
\hline 16 & 10 & 1 & 12 & 26 \\
\hline 9 & 21 & 19 & 13 & 3 \\
\hline 15 & 11 & & 14 & 25 \\
\hline 5 & 6 & 23 & 24 & 7 \\
\hline 20 & 17 & 22 & 2 & 4 \\
\hline
\end{tabular}

Berdasarkan hasil analisis pada azimat diatas, jumlah dari setiap elemen pada masing- masing baris, kolom dan kedua diagonalnya adalah 65. Maka azimat tersebut termasuk dalam variasi dari persegi ajaib (magic square).

iii. Azimat Memerangi Hawa Nafsu

Azimat ini digunakan untuk memerangi hawa nafsu dan tampak berwibawa dihadapan orang lain. Bentuk azimatnya adalah sebagai berikut:

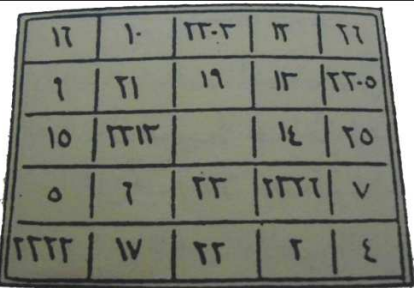

Gambar 19. Azimat Memerangi Hawa Nafsu (Sumber: As Syadhli halaman 44)

Azimat di atas jika diterjemahkan ke dalam lambang desimal akan diperoleh hasil seperti tabel di bawah ini:

Tabel 19. Lambang Desimal dari Azimat Memerangi Hawa Nafsu

\begin{tabular}{|c|c|c|c|c|}
\hline 16 & 10 & 2203 & 12 & 26 \\
\hline 9 & 21 & 19 & 13 & 2205 \\
\hline 15 & 2213 & & 14 & 25 \\
\hline 5 & 6 & 23 & 2226 & 7 \\
\hline 2222 & 17 & 22 & 2 & 4 \\
\hline
\end{tabular}

Berdasarkan hasil analisis pada azimat di atas, jumlah dari setiap elemen pada masingmasing baris, kolom dan kedua diagonalnya adalah 2267. Maka azimat tersebut termasuk dalam variasi dari persegi ajaib (magic square).

iv. Azimat Balas Dendam

Azimat ini digunakan untuk membalas dendam kepada orang yang telah menganiaya kita sampai orang tersebut meninggal dunia dan jika orang tersebut hidup maka diberikan hidup yang paling hina. Bentuk azimatnya adalah sebagai berikut:

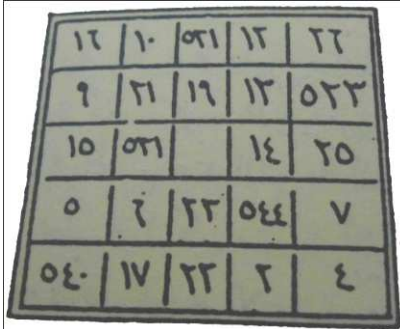

Gambar 20. Azimat Balas Dendam

(Sumber: As Syadhli halaman 45)

Azimat di atas jika diterjemahkan ke dalam lambang desimal akan diperoleh hasil seperti tabel 20.

Berdasarkan hasil analisis pada azimat pada tabel 20. Jumlah dari setiap elemen pada masing-masing baris, kolom dan kedua diagonalnya adalah 585. Maka azimat tersebut 
termasuk dalam variasi dari persegi ajaib (magic square).

Tabel 20. Lambang Desimal dari Azimat Balas Dendam

\begin{tabular}{|c|c|c|c|c|}
\hline 16 & 10 & 521 & 12 & 26 \\
\hline 9 & 21 & 19 & 13 & 523 \\
\hline 15 & 531 & & 14 & 25 \\
\hline 5 & 6 & 23 & 544 & 7 \\
\hline 540 & 17 & 22 & 2 & 4 \\
\hline
\end{tabular}

\section{Penjelasan Mengenai Azimat Numerik Berdasarkan Klasifikasi Persegi Ajaib (Magic Square)}

Wifiq atau wafaq bermakna selaras, serasi dan sistematis. Menurut istilah wafaq berarti tulisan yang berupa huruf, angka, simbol yang membentuk pola yang sistematis dan serasi yang diyakini akan membentuk pola energi yang dapat difungsikan sesuai dengan niat sang pembuat wafaq (Umar, 2010).

Keserasian dari wafaq adalah bila angkaangka dalam kotak persegi wafaq saling dijumlahkan secara vertikal, horisontal dan diagonal maka akan menghasilkan jumlah yang sama (dijumlahkan kebawah, kesamping ataupun miring, semua jumlahnya sama). Dengan modal tersebutlah dari sisi matematika dapat dijelaskan dengan konsep persegi ajaib (magic square).

Azimat numerik yang telah dikumpulkan dan dianalisis berdasarkan klasifikasi persegi ajaib (magic square) diatas terdapat enam klasifikasi, yaitu persegi semi-ajaib (semimagic square), persegi ajaib sempurna (perfect magic square), persegi ajaib simetris (syimetric magic square), persegi ajaib kosentrik atau bondered, persegi ajaib penjumlahan-perkalian (additionmultiplication magic square), dan variasi persegi ajaib.

Menurut analisis diatas maka secara matematik salah satu jenis azimat numerik yang berbentuk kotak merupakan azimat yang terdiri dari angka-angka atau simbol bilangan yang menggunakan bahasa Arab dan tidak memiliki khasiat atau kekuatan tertentu, melainkan pengembangan dari salah satu konsep matematika yaitu persegi ajaib (magic square). Selain itu, jika dilihat dari segi penulisan, tidak semua penulisan azimat tersebut benar. Terbukti pada saat penulis melakukan perhitungan, terdapat beberapa azimat yang kurang tepat dalam segi penulisannya. Kasus seperti ini dimungkinkan pada saat penulis buku tersebut menyalin dari buku-buku atau kitab-kitab sebelumnya terdapat suatu kemiripan angka (Arab) dan tidak dapat dilihat dengan jelas. berbunyi:

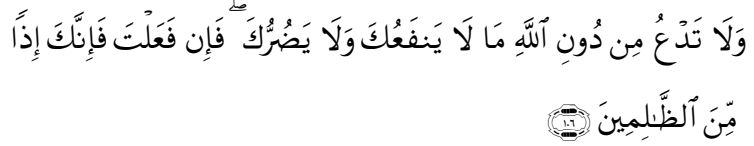

Artinya: "Dan janganlah kamu menyembah apa-apa yang tidak memberi manfaat dan tidak (pula) memberi mudharat kepadamu selain Allah; sebab jika kamu berbuat (yang demikian), itu, Maka Sesungguhnya kamu kalau begitu Termasuk orang-orang yang zalim".

Dari potongan ayat diatas menjelaskan bahwa, zalim yang dimaksudkan adalah zalim terhadap diri sendiri dengan mempercayai kekuatan pada azimat tersebut. Seseorang yang mempercayai sesuatu hal tanpa melihat dan mengetahui apa yang terkandung di dalamnya merupakan salah satu wujud perbuatan syirik.

\section{PENUTUP}

Hasil dari analisis matematik terhadap azimat numerik yang berbentuk tabel $n \times n$ terkonstruk dari konsep matematika yaitu persegi ajaib (magic square) dengan klasifikasi yaitu persegi semi-ajaib (semimagic square), persegi ajaib sempurna (perfect magic square), persegi ajaib simetris (symmetric magic square), persegi ajaib kosentrik (bondered), persegi ajaib penjumlahan-perkalian (addition-multiplication magic square), dan variasi persegi ajaib.

Azimat numerik pada bentuk tabel yang telah diteliti dalam pandangan matematika bukan merupakan sesuatu hal yang luar biasa serta tidak memiliki suatu kegunaan yang khusus, melainkan hanyalah sebuah tabel $n \times n$ yang angka didalamnya terkonstruk dari sebuah konsep matematika. Saat azimat disalin dari buku ke buku atau dari kitab ke kitab terdapat juga kesalahan tulisan karena kemiripan ataupun kesalahan percetakan.

Pada penelitian ini, penulis menganalisis azimat numerik yang berbentuk tabel. Selain azimat numerik terdapat juga azimat alfabetik dan azimat pictorial. Oleh karena azimat alfabetik telah diteliti, maka penulis memberikan saran kepada pembaca yang tertarik dengan permasalahan ini untuk mengembangkannya dengan meneliti dan menganalisis azimat numerik yang berbentuk selain tabel atau dengan meneliti dan menganalisis azimat pictorial.

\section{DAFTAR PUSTAKA}

[1] Alex, Persi. 2004. The Electronic Journal of Combinatorics 11(2). Journal: Stanford University

[2] Al-Ghozali. Al-Aufaq. Diambil dari Ponpes. Islam As-salafi 
[3] Al-Mashiri, Imam Abil Abbas Ahmad bin Alil Bauni. 1994. Sakti Mandra Guna. Pekalongan: T.B Bahagia

[4] Andrews, W. S. 1960. Magic Squares and Cubes. New York: Dover Publications, Inc.

[5] As-Syahdi, Abu Hasan. 1249 H. As-Sirul Jalil. Surabaya: Mahtabah Al-Hidayah

[6] Beck, Matthias dan Andrew Van Herick. 2010. American Mathematical Society: Enumeration of $4 \times 4$ Magic Squares. Mathematics of Computation: Article Electronically Published on March 29.

[7] Departemen Agama RI. 2007. Al-Qur'an dan Terjemahannya 30 Juz. Solo: PT Qomari Prima Publisher.
[8] Departemen Pendidikan dan Kebudayaan. 1989. Kamus Besar Bahasa Indonesia. Jakarta: Balai Pustaka

[9] Hanafi, Muhammad. 2000. Asma'ul Husna. Surabaya: Sinar Terang

[10] Rahman, Hairur. 2007. Indahnya Matematika dalam Al-Qur'an. Malang: UIN-Malang Press.

[11] Samsuri, Muhammad. 1998. Mujarrobat Besar. Surabaya: Apollo

[12] Stephens, Daryl Lynn. 1993. Matrix Properties of Magic Squares: Denton, Texas 